\title{
Three-Component Synthesis of (Pyrrolo)quinazolines
}

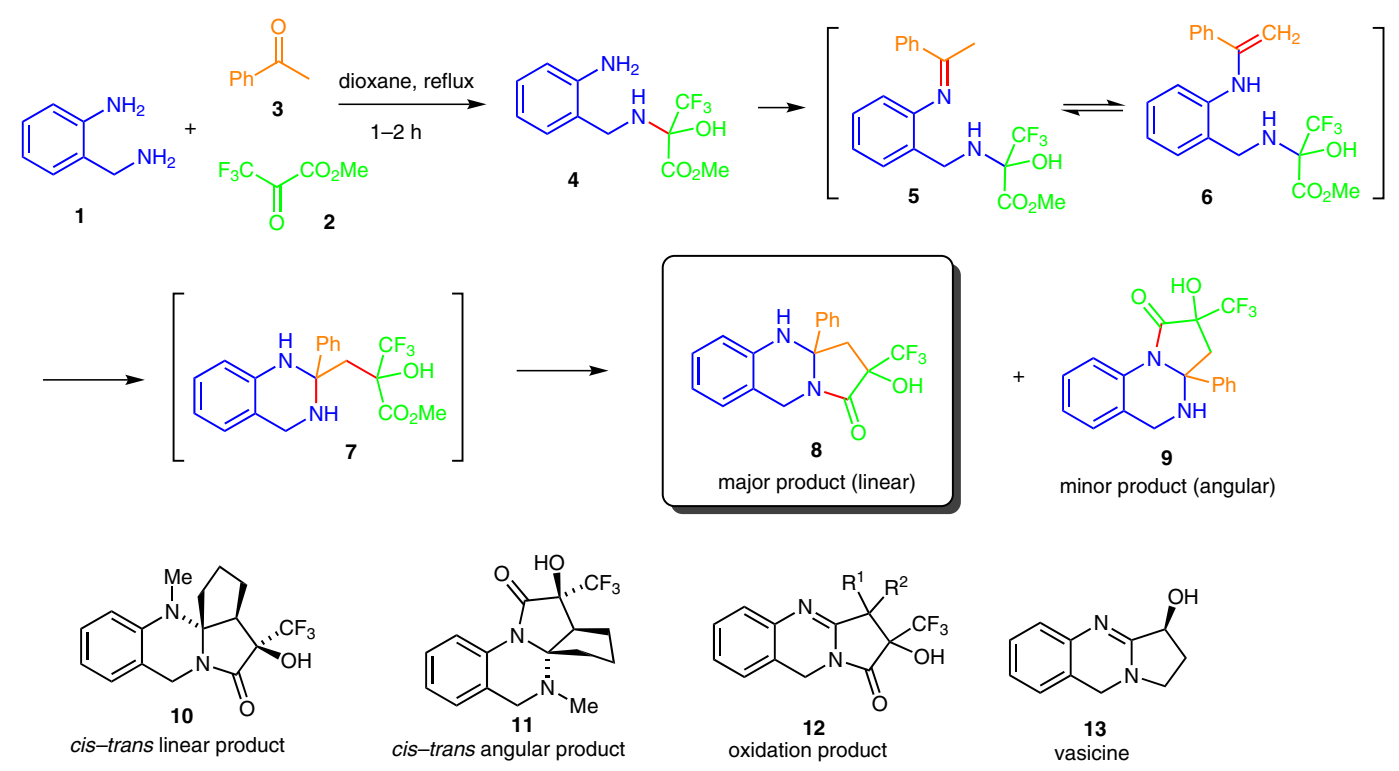

Gategory

Synthesis of

Heterocycles

Key words

three-component

reaction

pyrroloquinazolines

nucleophilic

rearrangement
Significance: By combining three components, 2-aminobenzylamine $\mathbf{1}$, a reactive carbonyl compound (such as trifluoropyruvate) $\mathbf{2}$, and a ketone (or aldehyde) 3, (pyrrolo)quinazolines are formed by a heteroannulation process which involves an interesting rearrangement from 6 to $\mathbf{7}$. A detailed mechanistic study of the process was carried out, providing evidence that the reaction proceeds via the hemiaminal $\mathbf{4}$ and Schiff base $\mathbf{5}$, which is in equilibrium with its enamine $\mathbf{6}$. This step is followed by an unusual intramolecular cyclizationmigration sequence. Alternative lactam ring closure occurs, forming the tricyclic products $\mathbf{8}$ or $\mathbf{9}$. The linearly annulated (pyrrolo)quinazoline 8 (major product) conveniently possess the skeleton of alkaloids of the vasicine group (13). The quinazoline derivatives in general exhibit a variety of biological activities.

sYNFACTS Contributors: Victor Snieckus, Ondřej Kysilka Synfacts 2014, 10(1), 0015 Published online: 13.12.2013 Dol: 10.1055/s-0033-1340415; Reg-No.: V14613SF
Comment: This report builds on previous work by the same authors on the synthesis of (pyrrolo)quinazolines and the reactivity of trifluoropyruvate hemiaminals (Eur. J. Org. Chem. 2013, 1262; J. Fluorine. Chem. 2005, 126, 745). The cyclization proceeds with high regio- and stereoselectivities for the particular carbonyl compounds and is temperature dependent. Complete selectivity of the reaction can be achieved utilizing $N$-monomethylated aminobenzylamine as a starting material, affording exclusively the linear or angular products $\mathbf{1 0}$ or $\mathbf{1 1}$ using cyclopentanone as the starting ketone. Certain linear products can be oxidized by the excess of trifluoropyruvate, forming 12 with complete regioselectivity. The authors unambiguously established the relative configuration on the stereogenic centers utilizing a sophisticated combination of homo- and heteronuclear NOE experiments (Magn. Res. Chem. 2010, 48, 375). 